\title{
Análise da maturidade de arranjos produtivos locais na Serra Gaúcha
}

\author{
Analysis of maturity of local productive arrangements in Serra Gaúcha \\ Análisis de madurez de los arreglos productivos locales en Serra Gaúcha
}

Recebido: 30/12/2021 | Revisado: 04/01/2022 | Aceito: 08/01/2022 | Publicado: 12/01/2022

Darlan Ariel Prochnow
ORCID: https://orcid.org/0000-0003-3699-074X
Universidade Regional do Noroeste do Estado do Rio Grande do Sul, Brasil
E-mail: darlan.prochnow@ sou.unijui.edu.br
Fabiana Baptista Maurer Gomes
ORCID: https://orcid.org/0000-0003-3333-0703
E-mail: fabibmg@ @mail.com
Nelson José Thesing
Universidade Regional do Noroeste do Estado do Rio Grande do Sul, Brasil
ORCID: https://orcid.org/0000-0001-7123-0717
E-mail: nelson.thesing @ unijui.edu.br
Johannes Miranda Meira
Universidade Regional do Noroeste do Estado Ro Rio Grande do Sul, Brasil
ORCID: https://orcid.org/ 0000-0001-5809-8598
Universidade Regional do Noroeste do Estado do Rio Grande do Sul, Brasil
E-mail: johannes.meira @ sou.unijui.edu.br
Ivani Schuster
ORCID: https://orcid.org/0000-0003-1449-4999
Universidade Regional do Noroeste do Estado do Rio Grande do Sul, Brasil
E-mail: ivani.schuster@ ufrgs.br

\begin{abstract}
Resumo
O artigo tem por objetivo identificar o nível da maturidade de Arranjos Produtivos Locais da Serra Gaúcha, no Rio Grande do Sul, constituídos por micro, pequenas e médias empresas, que apresentam entre si um conjunto de características próprias, na especialização de produtos/processos/tecnologias. Um processo em que os Arranjos contam com as políticas públicas, na organização e estruturação da governança, para qualificar a capacidade técnica dos atores, estimulando potencialidades endógenas, ativando o movimento associativo local, tornando-se um ambiente fértil, para verificar o nível da maturidade dos Arranjos. Para responder esse desafio, a pesquisa conta com o modelo de identificação do nível de maturidade de Pietrobon (2009). Ainda, o estudo conta com os resultados coletados, pelo questionário, que apresenta o mapeamento e padronização de processos, treinamentos, estrutura organizacional, melhoria contínua, relacionamento, certificação, parcerias, clima organizacional e tecnologia da informação, planejamento estratégico. Pelas lentes de Pietrobon (2009), foram estabelecidos os graus da maturidade de cada Arranjo, tendo presente a análise por dimensão, construindo uma equiparação entre dados da pesquisa, o que permitiu identificar o grau de maturidade, destacando-se em primeiro lugar, o Metalmecânico e Automotivo, em segundo, o Polo de Moda, em terceiro, o Moveleiro. Ainda, a pesquisa aponta que os Arranjos Produtivos Locais são mecanismos de desenvolvimento do setor de produtivo, especialmente ao contar com poder financiador e estruturante do Estado, que modela, auxilia na organização do Arranjo. No entanto, é determinante o fator humano local, o comprometimento dos membros, que modifica e amadurece o Arranjo.
\end{abstract}

Palavras-chave: Análise de maturidade; Arranjos produtivos locais; Governança.

\begin{abstract}
The article aims to identify the maturity level of Local Productive Arrangements, in Serra Gaúcha, in Rio Grande do Sul, made up of micro, small and medium-sized companies, which have a set of specific characteristics among themselves, in the specialization of products / processes / technologies. A process, in which, the Arrangements rely on public policies, in the organization and structuring of governance, to qualify the technical capacity of the actors, stimulating endogenous potentialities, activating the local associative movement, becoming a fertile environment, to check the level of maturity of the Arrangements. To answer this challenge, the research uses Pietrobon's (2009) maturity level identification model. Still, the study counts on the results collected, through the questionnaire, which presents the mapping and standardization of processes, training, organizational structure, continuous improvement, relationship, certification, partnerships, organizational climate and information technology, strategic planning. Through the lenses of Pietrobon (2009), the maturity degrees of each Arrangement were established, bearing in mind the analysis by dimension, building an equivalence between research data, which allowed the identification of the maturity degree, highlighting in the first place, the Metalmechanic and Automotive, in second, the Polo de Moda, in
\end{abstract}


third, the Furniture. Still, the research points out that the Local Productive Arrangements are mechanisms for the development of the productive sector, especially, as it has the financing and structuring power of the State, which models, assists in the organization of the Arrangement. However, the local human factor, the commitment of the members, which modifies and matures the Arrangement is decisive.

Keywords: Maturity analysis; Local productive arrangements; Governance.

\section{Resumen}

El artículo tiene como objetivo identificar el nivel de madurez de los Arreglos Productivos Locales, en Serra Gaúcha, en Rio Grande do Sul, constituidos por micro, pequeñas y medianas empresas, que presentan entre sí, un conjunto de características propias, en la especialización de productos / procesos / tecnologías. Un proceso en el que los Arreglos se apoyan en políticas públicas, en la organización y estructuración de la gobernanza, para capacitar la capacidad técnica de los actores, estimulando potenciales endógenos, activando el movimiento asociativo local, convirtiéndolo en un ambiente fértil, para verificar el nivel de la vencimiento de los Arreglos. Para responder a este desafío, la investigación utiliza el modelo de identificación del nivel de madurez de Pietrobon (2009). El estudio también incluye los resultados recolectados a través del cuestionario, que presenta el mapeo y estandarización de procesos, capacitación, estructura organizacional, mejora continua, relación, certificación, alianzas, clima organizacional y tecnologías de la información, planificación estratégica. A través de las lentes de Pietrobon (2009), se establecieron los grados de madurez de cada Arreglo, teniendo en cuenta el análisis por dimensión, construyendo una equivalencia entre los datos de investigación, lo que permitió identificar el grado de madurez, destacando en primer lugar, la Metalmecánica. y Automoción, en segundo lugar, el Polo de Moda, en tercero, el Mobiliario. Aún así, la investigación señala que los Arreglos Productivos Locales son mecanismos para el desarrollo del sector productivo, sobre todo porque cuentan con el poder de financiamiento y estructuración del Estado, que modela y ayuda en la organización del Arreglo. Sin embargo, es determinante el factor humano local, el compromiso de los socios, que modifica y madura el Arreglo.

Palabras clave: Análisis de madurez; Arreglos productivos locales; Gobernancia.

\section{Introdução}

A humanidade passa por significativas transformações, que provocam grandes alterações na sociedade, gerando incertezas de como entender e interagir com a realidade concreto da existência humana, que se transforma, igualmente, indica caminhos da pesquisa. Neste ambiente, estão os Arranjos Produtivos Locais (APL's), que se consolidaram nas últimas décadas, como um importante mecanismo de reestruturação e desenvolvimento no meio produtivo, utilizando principalmente os elos entre dois elementos - territórios e empresas (Dias, 2011).

Por conseguinte, os Arranjos se apresentam como um fenômeno, para pensar e planejar o desenvolvimento regional, que contam com políticas prioritárias de governos, para potencializar as diversidades culturais, sociais e econômica. Em um processo, que oportuniza a conquista da maturidade corporativa nos empreendimentos. Significa buscar um planejamento em todos os processos produtivos para melhorar o grau de maturidade dos Arranjos Produtivos Locais.

Portanto, o presente estudo busca operar sua pesquisa, para entender o grau de maturidade, tendo por base as orientações de Pietrobon (2009). Assim, tem-se presente que esse processo apresenta, entre outras características, a individualidade empresarial, por um lado e de outro, organizações que buscam ações coletivas, novos processos produtivos.

Assim, para verificar o grau de maturidade dos Arranjos Produtivos nos APL's: Metalmecânico e Automotivo, Polo de Moda e Moveleiro, a pesquisa conta com a base do modelo de identificação de maturidade de projetos, adaptado à realidade dos APL's de Pietrobon (2009), em um caminhar metodológico, que é operado por questionário estruturado, com perguntas de múltipla escolha, para verificar os treinamentos, mapeamento e padronização de processos, estrutura organizacional, planejamento estratégico, melhoria contínua, relacionamento, certificação, parcerias, clima organizacional e tecnologia da informação. As respostas foram agrupadas por APL, separando-as em dimensões, conforme propõe o modelo de Pietrobon (2009). Assim, o artigo está estruturando, com essa Introdução, em seguida as Fundações Teóricas, Caminhos Metodológicos, Análise e Discussão dos Resultados e as Considerações Finais. 


\section{Arranjos Produtivos Locais (APLs)}

Os Arranjos Produtivos Locais contam em sua conceituação, com um conjunto de fundamentos, princípios de integração, estruturação e aprendizagens, o que poderá auxiliar na compreensão do grau de maturidade, enquanto mecanismo estratégico para o planejamento de qualquer organização, inclusive para APL (Pinto, 2017). Tendo presente essa orientação, em 2011, o governo do estado do Rio Grande do Sul, passou a planejar uma alternativa para o desenvolvimento econômico gaúcho, apostando nos APL's. No primeiro ano foram apoiados cinco APL's: 1) Moveleiro, 2) Polo de Moda, 3) Metalmecânico e Automotivo, 4) Metalmecânico Pós Colheita e 5) Pedras, Gemas e Joias.

Esse processo de implantação dos APL's contou com os recursos do Programa de Apoio à Retomada do Desenvolvimento do Rio Grande do Sul (PROREDES), e do Banco Internacional para a Reconstrução e Desenvolvimento (BIRD) (Carrado \& Linhares, 2018).

Entende-se que o projeto APL's, desde sua gênese, tem por base a auto-organização das aglomerações industriais, presentes no programa, pelas ações transversais que desenvolvem a governança, para desta forma, aumentar a capacidade técnica dentro dos Arranjos. Esse caminhar busca maior eficiência produtiva das empresas, bem como, contribui com o desenvolvimento da economia regional. Além disso, o projeto dos APL's propõe atenuar os desequilíbrios regionais, ambientais e sociais (Espírito Santo, 2004).

Para Kapron (2014), entre outros objetivos, do desenvolvimento sustentável, está na primeira página da agenda, a centralidade, na equidade, na participação da sociedade local, para dinamizar a estrutura produtiva do Estado e fomentar investimentos estratégicos, apoiar a organização de atividades associativas.

Atenta-se para o processo de participação, na organização dos APL's, os mesmos podem ser entendidos como organismos vivos, apresentam em sua matriz produtiva, retratos de estabilidades humanas locais, nos quais há diferentes graus de maturidade. Mudanças políticas e de gestores nas instituições locais, tendem a afetar o funcionamento do Arranjo, tanto no sentido de sua fragilidade, quanto em seu fortalecimento (Costa, 2011).

Ao ter em vista as fragilidades e o fortalecimento, cotejar os conceitos dos APL's, no entender de Costa (2011), significa identificá-los como sendo um conjunto de aglomerações empresariais, localizadas em um mesmo território, que apresentam especialização produtiva, mantêm algum vínculo de articulação, interação, cooperação e aprendizagem entre si e com outros atores locais, tais como: governos, associações empresariais, instituições de crédito, ensino e pesquisa.

Portanto, para Schiavo (2015), conceito de Arranjo Produtivo Local é mais agregador do que uma rede, na medida em que o arranjo busca a articulação, interação e aprendizagem mútua e constante, porém, mantém-se a interdependência entre os agentes participantes do mesmo, o que nem sempre é possível em uma rede de cooperação.

Já para Puga (2003), um APL pode ser definido como uma concentração geográfica de empresas e instituições, que se relacionam em um setor particular, em geral inclui fornecedores especializados, universidades, associações de classe, instituições governamentais e outras organizações que proveem educação, informação, conhecimento e/ou apoio técnico.

Para Erber (2008) e Araújo (2009), o Arranjo Produtivo pode ser um mecanismo, pelo qual, agentes econômicos, políticos se organizam e se inter-relacionam para buscar soluções competitivas para os negócios empresariais. Seu eixo gravitacional busca o compartilhamento do desenvolvimento, não só por aspectos econômicos, mas também por aspectos geoeconômicos, tendo como finalidade estimular ambientes e ligações interorganizacionais.

No entender de Paiva (2004), o Arranjo Produtivo Local, pode ser considerado como fruto do desenvolvimento natural de uma aglomeração de empresas, ou um sítio de empresas especializadas, que induzem o desenvolvimento em seu entorno. Assim, as condições básicas referem-se à vários estágios e esforços compartilhados, estrutura de coordenação, cooperação interempresarial, capital social, caracterização competitiva, instituições de fomento, financiamento, pesquisa, 
serviços e políticas públicas adequadas ao desenvolvimento local e regional, além da existência da atividade econômica focal (Becker \& Wittmann, 2011).

A literatura científica destaca que algumas dificuldades podem ser resolvidas ou amenizadas, nos Arranjos Produtivos Locais, pela evolução de seus sistemas de governança, ao contar com as ferramentas de Avaliação de Desempenho (AD), são frequentemente citadas como um importante instrumento de apoio ao desenvolvimento gerencial (Biazzo \& Bernardi, 2003; Garengo, Nudurupati \& Bititci, 2007; Garengo, Biazzo \& Bititci, 2005), e desta forma estabelecer um relacionamento no Arranjo Produtivo para identificar e priorizar objetivos e ações que impactam positivamente na melhoria do desempenho das empresas individuais

\subsection{Governança em Arranjos Produtivos Locais}

A governança apresenta-se como um importante mecanismo de organização de um APL. Berle e Means (1932), foram os pioneiros nos estudos da governança corporativa, apresentando as concepções das modernas corporações, indicando uma separação entre o controle e gestão, todavia, a partir da década de 1980, o tema ganhou força em debates, na literatura internacional. Entre as várias concepções sobre governança, encontra-se num extremo, sobrevalorizam o caráter empresarialista, como governança urbana, no outro, concepções referentes às formas de governança democrática e compartilhada entre os atores sociais, institucionais, governamentais e empresariais (Dallabrida, 2015).

Assim, os conceitos de governança, indicam vários nortes de organização, no entanto, apontam um ponto comum, o que permite descrever a governança corporativa, como um conjunto de princípios e práticas que procuram minimizar os conflitos de interesse entre os agentes da companhia, com o objetivo de reduzir o custo de capital e aumentar o valor da empresa, bem como o retorno aos seus acionistas (Silva, 2006).

Por conseguinte, a trajetória da Governança Corporativa no Brasil, a iniciar em 1995, com a fundação do Instituto Brasileiro de Conselheiros de Administração (IBCA), atual Instituto Brasileiro de Governança Corporativa (IBGC), criado em 1999, que lançou o "Código das Melhores Práticas de Governança Corporativa", o primeiro código brasileiro sobre Governança Corporativa (IBGC, 2018). Para Rossetti e Andrade (2009), a governança possui abordagens que podem ser expressas pelas 8 (oito) dimensões, ou seja, os P's da governança: "Propriedade, Princípios, Propósitos, Papéis, Poder, Práticas, Perenidade e Pessoas" (Rossetti \& Andrade, 2012 p. 144).

Entende-se que em várias situações, o processo de governança, enquanto poder de decisão pode ser transferido ou compartilhado, surge um mecanismo de cooperação, como de conflito, entre os integrantes do Arranjo Produtivo. Esse movimento se dá pela presença das políticas públicas, empresas, associações, universidades, onde se manifestam interesses derivados da delegação de algum tipo de poder. Na essência, a governança trata da minimização de assimetrias e conflitos de interesses inerentes à delegação de poder (Filho, 2012), o que indica boas referências para pesquisas nestes ambientes.

Portanto, ao verificar as estratégias dos APL's, que apontam a necessidade de um processo colaborativo, uma intensa interação e manutenção das relações entre participantes, faz-se necessária a presença de uma estrutura de governança que proporcione maior sinergia nas ações, buscando atingir objetivos comuns convergentes entre os agentes. Assim, os processos decisórios, ao descentralizar e repartir o poder, contribuem na administração dos interesses, por vezes conflitantes, na realização das ações coletivas (Lastre, Cassiolato \& Arrio, 2005)

Desta forma, a governança poderá contar com a presença de órgãos de fomento, universidades, associações, empresas, órgãos públicos, fortalecendo o associativismo local (Fuini, 2013). Desta forma, a governança, pode ser um instrumento que proporciona a agregação de intenções e ações para a alavancagem do sucesso das atividades a serem realizadas no Arranjo.

Assim, na trilha da construção, de uma estrutura de governança, em um APL é sempre um caminho complexo, pelas demandas intensas, pelas interações e negociações entre os atores envolvidos, não podendo ser exercida por um comando 
centralizado (Tahim \& Araújo, 2014). Por isso, a interação entre as instituições e os atores sociais gera a necessidade de uma governança que minimize falhas de mercado e conflitos decorrentes das transações, especialmente olhar para os ativos envolvidos (físicos, humanos, locacionais de infraestrutura); da incerteza (mercado) a frequência de interações entre os atores presente no Arranjo.

Para Suzigan et. al. (2007), a estrutura de governança indica a presença de quatro pilares: a) interação entre ambientes interno e externo; b) interação entre conselho estratégico; c) interação entre todas as empresas e instituições correlatas e de apoio, assim como entre seus processos; e controle das ações. Esses aspectos reforçam, a importância de os atores do APL buscarem desenvolver ações conjuntas com vistas à eficiência coletiva.

\subsection{Arranjos Produtivos Locais e a Maturidade}

As novas tecnologias automatizam os processos e aumentam a velocidade da produção empresarial, consequentemente aceleram a capacidade individual de cada empresa. Porém, são os indivíduos mais suscetíveis às mudanças do meio, o que significa, em primeiro lugar conquistar os indivíduos, para articular mudanças empresariais. Diante dessa realidade, para atingir o maior número de empresas, faz-se necessário agir conjuntamente no meio empresarial, analisar a complexidade dos meios de produção e planejar estrategicamente um conjunto de ações para interferir na realidade e buscar as modificações indispensáveis para o desenvolvimento do Arranjo Produtivo.

Deste modo, buscar novos caminhos, para efetivar as ações do APL, o que significa planejar a governança, para desenvolver adequadamente o papel das lideranças no agrupamento das empresas participantes. Pela governança é possível conquistar altos níveis de maturidade corporativa, que potencialize as vantagens das relações dos membros na organização. A partir das relações das empresas envolvidas no Arranjo, podem ser tomadas atitudes coletivas que sejam benéficas para todos os membros do Arranjo, bem como oportuniza a redução dos custos, rateando-os entre os participantes, gerando com isso, ganhos de competitividade com menor investimento de recursos, segundo Pietrobon (2009).

Ao trabalhar as dimensões da maturidade de Pietrobon (2009), possibilita incorporar base teórica e metodológica do modelo conhecido como MMCP (Project Management Capability Maturity Model), ou também conhecido como PMM (Project Management Maturity Model), foi adaptado e definida como sendo uma forma para identificação do nível de maturidade para aglomerados produtivos. Para a validação do modelo proposto, a pesquisa verifica os aglomerados da Serra Gaúcha. Embora se tenha adotado o modelo MMGP, como base para desenvolver um modelo de identificação de maturidade para aglomerados produtivos, não se pode afirmar que seja possível que um único número demonstra claramente a maturidade de uma organização, e isto aplica-se também a aglomerados produtivos (Pietrobon, 2009).

Percebe-se que, para a especificação dos níveis e dimensões de maturidade para um aglomerado produtivo, faz-se necessária a implementação de uma relação entre os níveis de maturidade e a aderência com suas práticas. Para trabalhar esses desafios, a pesquisa conta com um questionário como forma de levantamento de dados, a fim de identificar o nível de aderência dos aspectos identificadores de maturidade (dimensões) e a maturidade alcançada. O questionário foi aplicado à coordenação dos APL's da Serra, contendo 40 (quarenta) perguntas divididas em 14 dimensões, sendo estas: 1) Aceitação do assunto; 2) Treinamento; 3) Gerencial; 4) Mapeamento e padronização de processos; 5) Estrutura organizacional; 6) Planejamento estratégico; 7) Melhoria contínua; 8) Relacionamento; 9) Governança; 10) Liderança; 11) Certificações; 12) Parcerias; 13) Clima organizacional e 14) Tecnologia da informação. 


\section{Metodologia}

Este trabalho segue um caminho sistemático para verificar a maturidade dos Arranjos, mapear dentro do possível, os próximos passos de desenvolvimento de cada organização. Assim, a pesquisa procura dentro do seu campo de atuação, entender a relação da teoria com a prática (Minayo; 2000).

O trabalho foi construído em dois momentos. Um de encaminhar os questionários, outro a utilização das técnicas de Pietrobon (2009), para a medição dos dados. Diagnosticou e analisou o nível de maturidade de três APL's da Serra Gaúcha (Moveleiro, Metalmecânico e Automotivo e Polo de Moda) utilizando um instrumento que possui 40 questões de múltipla escolha, contendo quatro alternativas para cada questão. As questões do instrumento estão divididas em 14 dimensões-chave, sendo que essas dimensões são consideradas situações constituintes da maturidade para APL.

O questionário foi preenchido por um agente representante da governança (E1), um agente membro do APL (E2) e um agente público vinculado aos movimentos e atividades do Arranjo na localidade (E3), com as contribuições, para a realização da pesquisa, levantadas pelas entrevistas com roteiro semiestruturado (Gil, 2017; Yin, 2015).

As respostas foram agrupadas por APL, separando-as em dimensões, conforme propõe o modelo de Pietrobon (2009). Em seguida foi quantificado cada resposta dos agentes, conforme os valores já previamente designados, calculado a média e o grau de maturidade, segundo o modelo, para em seguida correlacionar a resposta com a pontuação alcançada em cada dimensão, tendo como referência a análise dos dados, realizada pela análise de conteúdo, recomendada por Bardin (2016), pela categorização das entrevistas.

Por fim, para observar os eixos de mudança de cada APL e pontuar, foi necessário quantificar as dimensões de modo individual, depois comparar entre as porcentagens atingidas pelo APL, naquela dimensão. Os eixos escolhidos para comparação foram às últimas dimensões (Pietrobon) de cada nível. Para além, a pesquisa busca compreender os eixos de mudança de cada Arranjo, tendo como orientação a pesquisa qualitativa, no processo de comparação dos dados levantados e de técnicas, para maturidade dos Arranjos, verificar, na medida do possível, os passos de desenvolvimento de cada organização (Creswell, 2014; Yin, 2016).

\section{Resultados e Discussão}

Esta seção apresenta a análise e discussão dos principais resultados da pesquisa. Inicialmente são apresentados os resultados por Arranjo Produtivo. Após, é apresentada a análise comparativa entre os APLs.

\subsection{Resultados por Arranjo}

Cada Arranjo, objeto de estudo, teve como base as respostas obtidas, para identificar os pontos, em cada nível de maturidade. Para Pietrobon (2009) a aderência à maturidade demonstra que, quanto maior a pontuação obtida no questionário, maior será a maturidade referente à dimensão avaliada. A utilização dos valores obtidos a partir do questionário pode ser analisada de acordo com os seguintes critérios de níveis: a) Nula ou fraca (1 a 2); b) Regular (2 a 3); c) Boa (3 a 4); d) Completa (4 a 5).

Portanto, ao aplicar o questionário, junto aos agentes dos Arranjos Produtivos, na Serra Gaúcha, observa-se várias realidades em cada Arranjo, especialmente ao verificar o resultado, conforme a dimensão, é possível mapear como cada agente analisado está no processo proposto na dimensão. Assim, o Arranjo do Polo de Moda encontra-se em um grau de maturidade considerado bom, com a pontuação de 3,11 conforme o instrumento utilizado.

Desta forma, o Polo de Moda, apresenta em sua organização interna no sistema, estímulo e desenvolvimento, como buscas constantes, onde o nível de conhecimento técnico, apresentado pela equipe, foi identificado como adequado, em função 
dos resultados conquistado diante dos problemas de produção. Certamente esse processo contou com treinamentos junto aos colaboradores.

Já em relação aos aspectos organizacionais, bem como nas atividades do Polo de Moda, os agentes da governança apresentaram, em suas respostas, aspectos relacionado ao treinamento de boas práticas, para o gerenciamento de atividades de Arranjos Produtivos, ao contar com a utilizando planilhas, sequenciamento de tarefas e cronogramas, porém, apenas um pequeno número de agentes do Arranjo passou ao operar as ferramentas. Significa, por vezes, que os instrumentos funcionam como projetos pilotos.

No entanto, ao ser identificado uma nova atividade para o Arranjo, a governança busca o planejamento, desta atividade, consequentemente um plano de execução das atividades, onde se estabelece um modelo, com diferenciações entre atividades pequenas, médias e grandes. A pesquisa identificou que esse processo é sempre bem aceito pelos integrantes do Arranjo.

No campo de atuação dos Comitês, para acompanhamento das atividades, os mesmos foram implantados, porém, o grande desafio é coloca-los em funcionamento, na busca de sua efetividade. No entanto, as reuniões de avaliação, contam com os relatórios, o que leva a participação e na formulação das atividades. Já na área do planejamento técnico dos produtos no Arranjo, tem sido visto com qualidade razoável.

No quadro das dimensões, a pesquisa identificou a necessidade de um trabalho mais intenso, na busca da melhoria contínua, no modelo de gerenciamento. Já na dimensão da liderança, o estudo aponta certa deficiência, apontando a necessidade de conquistar avanços no processo de negociação, na área dos conflitos, na motivação. Esse processo necessita contar com a ampliação do Plano de Trabalho, sob a liderança da governança.

No que diz respeito à unificação e certificação de processos e/ou produtos que possam caracterizar o Arranjo, como característica de procedência, existe um alinhamento de ideias ainda que incipiente, porém, sem implementação. Mesmo que a maioria dos associados tenha certificação individual de seus produtos.

O Arranjo Moveleiro apresenta um grau de maturidade de 2,50, estando em estágio regular, razoavelmente conhecido pela comunidade. Porém, a administração do Arranjo, estimula o seu constante crescimento e desenvolvimento, pelas atividades, ofertando instrumentos de gestão. No entanto, não conquistou a simpatia de profissionais da alta administração. Existe um sistema informatizado, superior a um ano, porém, apenas um pequeno número de membros tem acesso. No que se refere aos Comitês de Atividades, os mesmos estão formados e caracterizados, se reúnem a mais de um ano, planejamento os próximos anos dos Comitês. Porém, não existe uma disciplina pré-estabelecida para este processo. O acompanhamento nas atividades é feito informalmente pelo coordenador do Arranjo.

No campo do processo de melhorias contínuas, esse é praticado pelo controle, que recebe a atenção pela medição da metodologia e do sistema implementado pelo Arranjo. Essas ações recebem uma avaliação interna, com reconstruções, porém, não há como avaliar os efeitos, em função da efetivação recente.

Quanto aos relacionamentos dos membros, o Arranjo dá muita importância observando sua complexidade, porém, não há nenhuma atividade prevista para dinamizar ou otimizar tal quesito. Assim, a governança exercida pelo coordenador do APL é estimulada a atingir suas metas, porém, não existe um sistema de avaliação. Mesmo assim, o coordenador é fortemente estimulado a atingir suas metas com relação ao Arranjo. Nas parcerias, existe um banco de dados aceitável, que atende parcialmente as necessidades, porém, utilizado eventualmente. Existe uma boa inter-relação entre os associados do Arranjo. A informatização é relativamente boa, tem um alinhamento de 50\% com os associados, mas existem vários aspectos a serem melhorados.

O nível de maturidade do Arranjo Metalmecânico e Automotivo é de 3,29, considerado bom. A alta administração, os gerentes e os proprietários das empresas estimulam o desenvolvimento do Arranjo, pelo processo de participação ativa. Já a 
equipe envolvida nas atividades do Arranjo, possuem um bom nível de conhecimento técnico, sobre as áreas onde o arranjo está envolvido, porém, faz-se necessário buscar constantemente treinamentos.

No campo do alinhamento das atividades executadas no Arranjo, desenvolvidas nos negócios dos membros, foram criados critérios, para que novas atividades sejam aceitas e alinhadas, com os negócios dos membros. Esses critérios têm sido respeitados por grande parte dos membros. Já no tocante ao mapeamento gerencial praticamente todos os gerentes/membros foram treinados, mas o treinamento abordou uma quantidade insuficiente de áreas com relação aquelas identificadas como necessária para a alta a administração. No atual momento não existe nenhuma intenção de construir um treinamento para os gerentes do Arranjo.

$\mathrm{Na}$ área da estrutura organizacional, foi realizada uma avaliação para identificar o tipo de estrutura organizacional mais adequada, possível e acordada com todos os membros do Arranjo. Quanto ao Comitê, o mesmo não foi implementado. Foi identificado a necessidade de um maior planejamento das atividades, porém, é entregue relatório para o Arranjo, para o registro e consulta futura atividades.

No planejamento estratégico, os produtos/serviços oferecidos pelo Arranjo, são considerados de alto nível técnico, onde foi criado um banco, com uma quantidade de informações para planejar futuras atividades. Os portfólios e programas recebem um atendimento especial, tendo o seu próprio gerente, além do coordenador do Arranjo. Esse gerenciamento é feito em fina sincronia com o responsável pelas metas estratégicas do Arranjo.

Existe um programa de melhoria contínua que não é bem entendido pelos envolvidos e/ou não funciona e/ou não é utilizado adequadamente. Todas as principais causas de fracasso foram identificadas e estabelecidas contramedidas para evitar que estas se repitam e esse trabalho está sendo implementado.

A relação na estrutura organizacional existe, é possível afirmar que a mesma foi implementada para governar o relacionamento entre os membros e o aglomerado produtivo. Os membros do Arranjo possuem e exercem a autoridade necessária e adequada. Não existe nenhum tipo de sistema de avaliação da governança, pelo qual se verifica se suas metas foram cumpridas, porém, há sempre prestações de conta.

Em relação ao alinhamento das atividades executadas no Arranjo, em relação aos negócios dos membros, foram criados critérios, para que novas atividades sejam aceitas e alinhadas com os negócios dos membros. Esses critérios têm sido respeitados por grande parte dos membros.

A pesquisa registra que totalidade dos membros do Arranjo, são altamente avançados no que se refere aos assuntos, como negociação, liderança, motivação e gestão de conflitos. O Arranjo metalmecânico e automotivo é visto e citado como benchmarking em gerenciamento de projetos, recentemente recebeu visitas de outras organizações para conhecer o sistema de gerenciamento de projetos. A informatização implantada é boa, porém, há vários pontos a serem melhorados. $\mathrm{O}$ alinhamento dos membros com os projetos do Arranjo é de $80 \%$ a $90 \%$.

\subsection{Análise comparativa entre os três Arranjos}

Para compreender os três Arranjos, foi realizado um corte vertical para buscar os pontos que divergiram em sua caminhada na maturação. Foram escolhidas as últimas dimensões de cada nível, sendo elas: Treinamento gerencial; estrutura organizacional; certificação e tecnologia da informação. O critério atribuído para essa escolha foi a impossibilidade de passar para o outro nível, sem fechar de forma satisfatória o nível anterior.

No Quadro 1, apresenta-se as informações para a visualização das dimensões escolhidas e comparação da maturidade dos Arranjos. Percebe-se que ao analisar apenas o grau, chega-se a um indicativo, porém, a análise fica incompleta.

Constata-se que em todas últimas dimensões de Pietrobon (2009) e dos níveis Prado (2004), o polo metalmecânico e automotivo tem um aproveitamento maior. 
Quadro 1. Comparativo da maturidade.

\begin{tabular}{|c|c|c|c|}
\hline & \multicolumn{3}{|c|}{ APL } \\
\hline & MODA & MOVELEIRO & $\begin{array}{c}\text { METALMECÂNICO } \\
\text { E AUTOMOTIVO }\end{array}$ \\
\hline Treinamento Gerencial & $63,3 \%$ & $48,3 \%$ & $63,3 \%$ \\
\hline Estrutura Organizacional & $77,3 \%$ & $57,3 \%$ & $78,6 \%$ \\
\hline Certificação & $20,0 \%$ & $13,3 \%$ & $43,3 \%$ \\
\hline Tecnologia da Informação & $26,6 \%$ & $26,6 \%$ & $40,0 \%$ \\
\hline
\end{tabular}

Fonte: Autores (2021).

Observa-se que nas duas primeiras dimensões apontadas para avaliação comparativa, treinamento, a estrutura organizacional, os índices pouco diferem. Acredita-se que é na primeira fase da fundamentação do Arranjo, da estruturação das atividades a serem executadas no futuro, é que esses quesitos foram tão próximos. Nessas primeiras dimensões observa-se também uma atuação mais forte do poder público, podendo ser através de treinamento ou de financiamento.

Registra-se que o treinamento é um instrumento imprescindível, dentro das organizações, sua utilização adequada é muitas vezes, a solução para inúmeros problemas. É onde alinha os agentes, com os objetivos estratégicos. Equipes que muitas vezes não possuem o conhecimento necessário, para executar satisfatoriamente suas atividades, consequentemente acabam se desmotivando e não contribuem como poderiam para a correta execução das operações.

A estrutura organizacional pode ser visualizada tanto no sentido físico, quanto dos elementos de trabalho, ou mesmo, de ambos. Compreende a disposição das diversas unidades que compõem a empresa e também as relações entre superiores e subordinados. Demonstram deveres e responsabilidades, autoridade e como a organização é estruturada, ela representa o organismo da empresa. E, nesse quesito, dois dos Arranjos demonstram seus índices com proximidade. Arranjo Polo de Moda: 77,3\%; Metalmecânico e Automotivo 78,8\%. Até essa fase, se observa uma grande força do poder público nos Arranjos, no sentido de fortalecer elos entre os agentes, estruturar mecanismos para uma política eficaz de desenvolvimento.

Entende-se que o distanciamento maior ocorre, ao observar o fator autonomia, sustentabilidade de cada Arranjo, onde se faz necessário, a inserção do poder público, para auxiliar nas questões estratégicas, especialmente, de como se colocar localmente com maior amplitude no mercado.

$\mathrm{Na}$ etapa seguinte, foi objeto de estudo, a dimensão 11, a certificação, que serve para dar conformidade, padronização ou até atestado de origem, buscando sempre agregar valor ao produto. Neste quesito, nos três Arranjos não foi apresentada qualquer tipo de certificação coletiva registrada, apenas, foi apontado que alguns agentes de modo individual possuíam seus próprios certificados. Os Arranjo que que vem trabalhando em uma certificação de indicação geográfica, é o metalmecânico e automotivo, já que se encontram em situação de referência nacional.

Ainda, nos Arranjos Metalmecânico e Automotivo, foram identificadas as diretrizes dos Arranjos, estão todas claras a mais de 2 anos para os dirigentes, e/ou pelo menos há 1 ano para todos os membros. E todas as atividades dos membros tendem a seguir parâmetros do Arranjo. 
A última dimensão apontada como parâmetro de comparação, entre os Arranjos, é a dimensão, tecnologia da informação, onde através dela se instrumentaliza a padronização de processos, dinamiza a comunicação entre os membros, facilita a busca pelo banco de dados e constroem um sistema mais ágil. Nesse quesito os Arranjos Metalmecânico e Automotivo se destacam.

\section{Considerações Finais}

A pesquisa apresenta como objeto de estudo, os Arranjos Produtivos da Serra Gaúcha: Moveleiro, Metalmecânico e Automotivo e Polo de Moda, identificando o nível de maturidade dos aglomerados produtivos, pelo instrumento proposto por Pietrobon (2009). Esse processo possibilita quantificar o processo de crescimento, o fator da inovação.

Analisar os três Arranjos, da Serra Gaúcha, que tem em sua gênese, um conjunto de pontos que convergem, resultados que aparentemente são até próximos, faz com que a análise seja parcial, porém, ao analisar cada dimensão proposta de Pietrobon (2009) de forma comparativa, com um outro Arranjo da região é possível observar que o poder financiador e estruturante do Estado, durante o tempo em que está presente, modela, segura a organização do Arranjo. No entanto, é determinante o fator humano local, o interesse dos membros envolvidos, que modifica e amadurece o Arranjo.

Significa que a presença do Estado, se apresenta enquanto processo semelhante à de uma incubadora, ou/e uma instituição que se faz necessária durante os primeiros anos. No entanto, aos poucos o Arranjo conquista um espaço, na medida em consegue dar suporte aos sócios, o que estimula a presença de novos membros no Arranjo, o que poderá ser um fator de sustentabilidade. Assim, o Arranjo, não é somente resultado de uma política pública de desenvolvimento, mas passa a ser um meio de produção e desenvolvimento local.

Por conseguinte, a pesquisa identificou uma realidade dos Arranjos, especialmente, apresenta uma visão de cada associado, que fundamentalmente busca desenvolver sua produção, se desenvolver como empreendimento local, que necessita olhar para suas atividades, na região e fora dela, para buscar sua sustentabilidade, o que significa acompanhar os estudos de maturidade de Pietrobon (2009), que mostram uma importante análise individual de cada Arranjo, bem como, uma análise comparativa entre os Arranjos, que possuem territorialidade em comum, para assim analisar a saturação de cada eixo e quais os movimentos que não foram executados com competência, capazes de impulsionar os próximos níveis de maturidade. Portanto, a pesquisa traz em sua constituição, mecanismos e instrumentos de medição e análise de Arranjos Produtivos e aponta modus de ação e retomada, como e quando for possível e desejado a conquista de novos níveis de maturidade do Arranjo.

Para trabalhos futuros, recomenda-se a utilização da metodologia de Pietrobon (2009), como ferramenta de ações futuras, junto aos Arranjos Produtivos, para nortear planejamentos estratégicos, após a análise comparativa de maturidade dos Arranjos e fomentar a saturação dos eixos de mudanças.

\section{Referências}

Araújo, M. J. (2009). Fundamentos de agronegócios. São Paulo: Atlas.

Bardin, L. (2016). Análise de conteúdo. São Paulo: Edições 70.

Becker, D. F. Wittmann, M. L. (2011). Desenvolvimento regional: abordagens interdisciplinares. Santa Cruz do Sul: Edunisc.

Berle, A.; Means, G. (1932). The Modern Corporation and Private Property. New York: McMillan.

Biazzo, S.; Bernardi, G. (2003) Organisational self-assessment options: a classification and a conceptual map for SMEs. International Journal of Quality \& Reliability Management, v. 20 n. 8.

Carraro, A.; Linhares, S. S. (2018). Análise setorial do impacto da política dos APL's no Rio Grande do Sul. Interações (Campo Grande), v.19, n.3. 
Costa, O. M. E. da. (2011). Arranjos Produtivos Locais. APL's como estratégia de desenvolvimento: uma abordagem teórica. Fortaleza: Instituto de Pesquisa e Estratégia Econômica do Ceará (IPECE).

Creswell, J. W. (2014). Investigação qualitativa \& projeto de pesquisa: escolhendo entre cinco abordagens. Porto Alegre: Penso.

Dallabrida, V.R. (2015). Governança Territorial: do Debate Teórico à Avaliação da sua Prática. Análise Social, v.2a 2015.

Dias, C. N. (2011). Arranjos Produtivos Locais (APL's) como Estratégia de Desenvolvimento. Editora Unijuí, v.9, n.17.

Erber, F. S. (2008). Eficiência coletiva em arranjos produtivos locais industriais: Comentando o conceito. Belo Horizonte: Nova Economia.

Espirito Santo (Estado). (2004) Secretaria de Estado de Desenvolvimento (SEDES). Núcleo Estadual de Arranjos Produtivos Locais do Espírito Santo (NEAPL/ES). Termo de Referência Para Atuação do Núcleo Estadual de APL do Espírito Santo.

Filho, F; Lins, J. (2012). Fundamentos e Análises das Demonstrações Contábeis: uma Abordagem Interativa. São Paulo: Atlas.

Fuini, L. L. (2013) Abordagem dos sistemas agroalimentares localizados (SIAL) e sua governança: Reflexões sobre o desenvolvimento dos territórios. Estudos Geográficos, Rio Claro, SP, vol. 11, n. 2.

Gil, A. C. (2017). Como elaborar projetos de pesquisa. São Paulo: Atlas.

Gonçalves, J. C. (2000). Avaliação do Centro Tecnológico Moveleiro no "Cluster" Industrial de Móveis da Região de São Bento do Sul. $2000152 \mathrm{f}$. Dissertação (Mestrado em Economia) - Universidade Federal de Santa Catarina, Florianópolis, SC.

Garengo, P.; Biazzo, S.; Bititci, U. (2005). Performance measurement systems in SMEs: A review for a research agenda. International Journal of Management Reviews, v. 7, n. 1, mar.

Garengo, P.; Nudurupati, S.; Bititci, U. (2007). Understanding the relationship between PMS and MIS in SMEs: an organizational life cycle perspective. Computers in Industry, v. 58, n. 7.

Ibgc - Instituto Brasileiro de Governança Corporativa. (2015). Código das Melhores Práticas de Governança Corporativa. $5^{\text {a }}$.ed. / Instituto Brasileiro de Governança Corporativa. - São Paulo, SP: IBGC.

Kapron, S. (2014). Os arranjos produtivos locais, extensão produtiva e inovação; (re) construindo a política pública de desenvolvimento. In: Montero, G. C.F et al. (org.). Um olhar territorial para o desenvolvimento Sul. Rio de Janeiro: BNDES. cap. 17.

Lastre, H. M. M.; Cassiolato, J. E.; Arroio, A. (2005). Conhecimento, sistemas de inovação e desenvolvimento. Rio de Janeiro: UFRJ, 2005

Minayo, M. C. de S. (1998). Ciência, Técnica e Arte: o desafio da pesquisa social. In: Minayo, M. C. de S. (Org.). Pesquisa Social: teoria, método e criatividade. 8 ed. Petrópolis: Vozes.

Paiva C. A.N. (2004). Como identificar e mobilizar o potencial de desenvolvimento endógeno de uma região? Porto Alegre: Fundação de Economia e Estatística.

Pietrobon, F. (2009). Proposta de um modelo para identificação do nível de maturidade de aglomerados produtivos. 116 f. Dissertação - Curso de Programa de Pós-Graduação em Engenharia de Produção Ppgep, Gerência de Pesquisa e Pós-Graduação, Universidade Tecnológica Federal do Paraná, Ponta Grossa.

Pinto, R. L. (2017). Avaliação do nível de maturidade em gerenciamento de riscos de projetos em uma empresa de automação. $140 \mathrm{f}$. Dissertação (Mestrado em Sistemas de Gestão) - Universidade Federal Fluminense. Escola de Engenharia, Niterói.

Puga, F. P. (2003). Alternativas de apoio a MPMES localizadas em arranjos produtivos locais. [S.L.]: BNDES, 2003.

Prado, D. S. (2004) Gerenciamento de portfólios, programas e projetos nas organizações. Nova Lima, MG: INDG.

Rossetti, J. P.; Andrade, A. (2012). Governança Corporativa: Fundamentos, Desenvolvimento e Tendências. (6a. ed.). São Paulo: Atlas.

Silva, A. L.C. (2006). Governança Corporativa e Sucesso Empresarial: Melhores Práticas para Aumentar o Valor da Firma. São Paulo: Saraiva.

Schiavo, C. (2015). Um estudo sobre o Arranjo Produtivo Audiovisual no Rio Grande do Sul no contexto da economia da cultura. 2015. 82f. Monografia (Bacharelado em Economia) - Faculdade de Ciências Econômicas, Universidade Federal do Rio Grande do Sul, Porto Alegre, RS.

Suzigan, W; Garcia, A. R; Furtado, J. (2007). Estruturas de governança em arranjos ou sistemas locais de produção. Campinas: Gestão \& Produção, 14.

Tahim, E. F., Araújo, I. F. Jr. (2014) A carcinicultura do nordeste brasileiro e sua inserção em cadeias globais de produção: foco nos APL's do Ceará. Revista de Economia e Sociologia Rural, 52(3).

Yin, R. K. (2015). Estudo de caso: planejamento e métodos. Porto Alegre: Bookman.

Yin, R. K. (2016). Pesquisa qualitativa do início ao fim. Porto Alegre: Penso. 